\title{
Utilization of Google Earth for Distribution Mapping of Cholangiocarcinoma: a Case Study in Satuek District, Buriram, Thailand
}

\author{
Wannaporn Rattanasing ${ }^{1}$, Soraya J Kaewpitoon ${ }^{2,3}$, Ryan A Loyd ${ }^{3}$, Ratana \\ Rujirakul $^{2}$, Eakachai Yodkaw ${ }^{4}$, Natthawut Kaewpitoon ${ }^{2,5 *}$
}

\begin{abstract}
Background: Cholangiocarcinoma (CCA) is a serious public health problem in the Northeast of Thailand. CCA is considered to be an incurable and rapidly lethal disease. Knowledge of the distribution of CCA patients is necessary for management strategies. Objectives: This study aimed to utilize the Geographic Information System and Google Earth ${ }^{\mathrm{TM}}$ for distribution mapping of cholangiocarcinoma in Satuek District, Buriram, Thailand, during a 5-year period (2008-2012). Materials and Methods: In this retrospective study data were collected and reviewed from the OPD cards, definitive cases of CCA were patients who were treated in Satuek hospital and were diagnosed with CCA or ICD-10 code C22.1. CCA cases were used to analyze and calculate with ArcGIS 9.2, all of data were imported into Google Earth using the online web page www.earthpoint.us. Data were displayed at village points. Results: A total of $\mathbf{5 3}$ cases were diagnosed and identified as CCA. The incidence was $\mathbf{5 3 . 5 7}$ per 100,000 population (65.5 for males and 30.8 for females) and the majority of CCA cases were in stages IV and IIA. The average age was 67 years old. The highest attack rate was observed in Thung Wang sub-district (161.4 per 100,000 population). The map display at village points for CCA patients based on Google Earth gave a clear visual deistribution. Conclusions: CCA is still a major problem in Satuek district, Buriram province of Thailand. The Google Earth production process is very simple and easy to learn. It is suitable for the use in further development of CCA management strategies.
\end{abstract}

Keywords: Cholangiocarcinoma - Google Earth - Satuek district - Burirum province - Thailand

Asian Pac J Cancer Prev, 16 (14), 5903-5906

\section{Introduction}

Cholangiocarcinoma (CCA) is a malignant tumor, arising from biliary epithelium at any portion of the biliary tree, characterized by a bad prognosis and poor response to current therapies. CCA is currently classified as intrahepatic or extrahepatic (Bragazzi et al., 2012). CCA has a worldwide distribution and accounts for about $10-15 \%$ of all cases of primary hepatobiliary malignancy (Parkin et al., 1993; Parkin, 2006). CCA is relatively rare, but high incidence rates have been reported in Eastern Asia, especially in Thailand (Shin et al., 2010; Sripa et al., 2011). CCA is reported frequently in Thailand, and found the highest of the world (Sripa et al., 2007; Kaewpitoon et al., 2008). The experimental and epidemiological evidences strongly indicated that the liver fluke infection in the etiology of CCA (Thamavit, et al., 1978; Parkin et al., 1993; IARC, 1994; Jongsuksuntigul and Imsomboon, 2003; Parkin, 2006; Sripa, et al., 2007; Shin et al., 2010). $\mathrm{CCA}$ is considered to be an incurable and rapidly lethal disease unless all the tumors can be fully resected. Since the operability of the tumor can only be assessed during surgery in most cases (Su et al., 1996), a majority of patients undergo exploratory surgery unless there is already a clear indication that the tumor is inoperable (Feldman et al., 2006). In Thailand, most CCA patients see a physician at a late stage when curative treatment is not possible. After diagnosis, they generally are treated by partial surgery/percutaneous drainage, chemotherapy and supportive treatment. The hospital-based cancer registry of Srinagarind Hospital, Khon Kaen University, the cumulative $3,6,9,12$ and 24 months survival rates were $59 \%, 39 \%, 31 \%, 24 \%$ and $14 \%$, respectively. The median survival time after supportive treatment was 4 months. Those in stage III and stage IV had a 6.78 fold higher mortality than the stage I and stage II cases (95\% CI: 1.6-28.7) (Thunyaharn et al., 2013). The outcome is poor although systemic management has been used in attempts to improve disease control, quality of life and prolong survival in patients with CCA.

${ }^{I}$ Environmental Managent Technology Program, Faculty of Science and Technology, Nakhon Ratchasima Rajabhat University, ${ }^{2}$ Parasitic Disease Research, ${ }^{3}$ Department of Family Medicine and Community Medicine, Institute of Medicine, Suranaree University of Technology, ${ }^{5}$ Master of Public Health Program, Vongchavalitkul University, Nakhon Ratchasima, ${ }^{4}$ Division of Family Medicine and Community Medicine, Satuek Hospital, Buriram, Thailand *For correspondence: natthawut.k@hotmail.com 
Geographic information system (GIS) and Google Earth $^{\mathrm{TM}}(\mathrm{GE})$ are a powerful tool for the storage and management, as well as analysis of natural and cultural data, increasing studies have applied the spatial statistical method of GIS in health sciences, for example, Kheifets et la., (2015) conducted a large epidemiologic casecontrol study in California to examine the association between childhood cancer risk and distance from the home address at birth to the nearest high-voltage overhead transmission line. Distance measures based on GIS and GE evaluation showed close agreement (Pearson correlation $>0.99$ ). Wattanayingcharoenchai et al. (2011) determined the surveillance characteristics of Opisthorchis viverrini infections in northeast Thailand; relative agent associated to CCA . The GIS was deployed to overlay the prevalence of disease on urban and agricultural areas as well as manmade land uses. Wongsaroj et al. (2012) studied helminthiasis in Thailand using GIS. The study results demonstrate that spatial analysis can help to identify patterns of high risk for liver fluke, O. viverrini in order to facilitate prevention and control. Marek et al. (2015) using geovisual analytics in GE to understand campylobacteriosis distribution in the Czech Republic during 2008-2012, prove that GE software is a usable tool for the geovisual analysis of the disease distribution. GE has many indisputable advantages (widespread, freely available, intuitive interface, space-time visualization capabilities and animations, communication of results). Wang et al. (2014) make various schistosomiasis epidemic maps based on GE, indicated that schistosomiasis epidemic maps are clear and visual. The production process is very simple and easy to learn. It is suitable for the use in the grass-root schistosomiasis control stations.

The aim of this article is to prove the applicability of GE software as a tool for geovisual analytics that helps to understand the spatio-temporal patterns of the CCA distribution map help in identifying areas where vulnerability is high for decision-making and planning in order to prevent or control the spread out of the disease in the future.

\section{Materials and Methods}

\section{Study location}

Satuek district is located 40 kilometer northeastern part of Buriram province, northeastern Thailand (It is approximately 450 kilometer from Bangkok), covers an area of 803.0 square kilometers (310.0 sq mi) with geographical location between Latitude $15^{\circ} 17^{\prime} 51^{\prime \prime} \mathrm{N}$ and Longitude $103^{\circ} 17^{\prime} 31^{\prime \prime} \mathrm{E}$. The district consists of $12 \mathrm{sub}-$ districts, and 120 villages. There are further 12 district administrative organizations, included Satuek, Nikhom, Thung Wang, Mueang Kae, Nong Yai, Ron Thong, Don Mon, Chum Saeng, Tha Muang, Sakae, Sanam Chai, and Krasang (Figure 1). The district has a population of about 110,191 people. The population density in Sateuk district is 139.19 per person square kilometers and more focused at rural and village. The main working sector is agriculture, labor, government officer, trading, and student (Provincial Administrative Organization of Buriram, 2012).

\section{Data collection}

CCA patient data were collected and reviewed form the out patient department (OPD) card of Satuek hospital, Buriram province. All cases were defined as CCA patients who were treated in Satuek hospital, and they were diagnosed CCA or ICD-10 code is C22.1. This data included information about sex, age group, adress, and CCA stage. Geographic data were collected from the Province Administrative Organization of Buriram, Thailand. Satellite data were collected from GeoInformatics and Space Technology Development Agency (Public Organization), Thailand. The study protocol was approved by Suranaree University Ethical Review Committee (2008).

\section{Data analysis}

Geographic information system (GIS) was used in this studied and Google Earth ${ }^{\mathrm{TM}}$ software as a tool for geovisual analytics. Village point, where had the CCA case, was used to analyze and calculate with ArcGIS 9.2. After the conversion, all of the data were imported into GE using online web pages www.earthpoint.us. This web pages using HTML codes to export the coordinate to $\mathrm{kml}$ format that can be recognized by GE. Nowadays, the data can be viewed in GE, Figure 2 indicating all of the case locations are spread on the map.

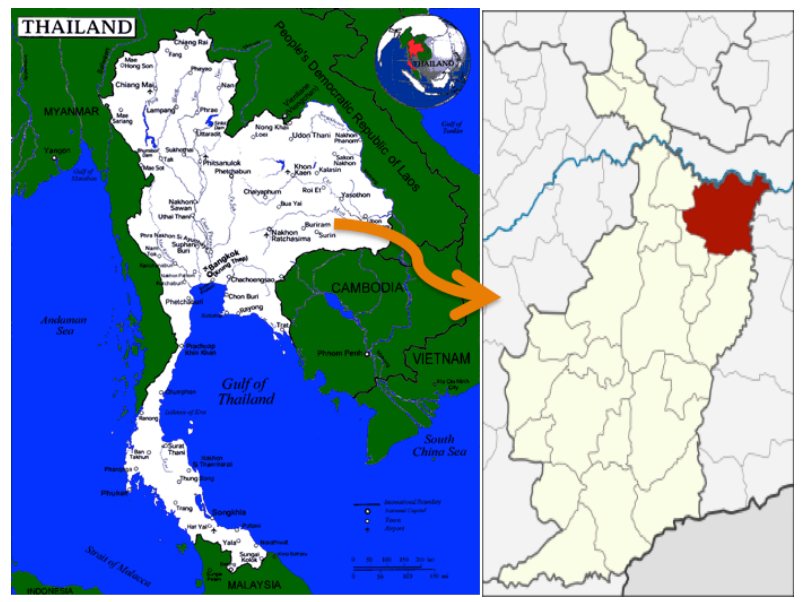

Figure 1. Map of Stuek distric, Buriram Province of Thailand; Red Color is Satuek District, (adapted from http://www.thailandmissions.org/thaimap.png.)

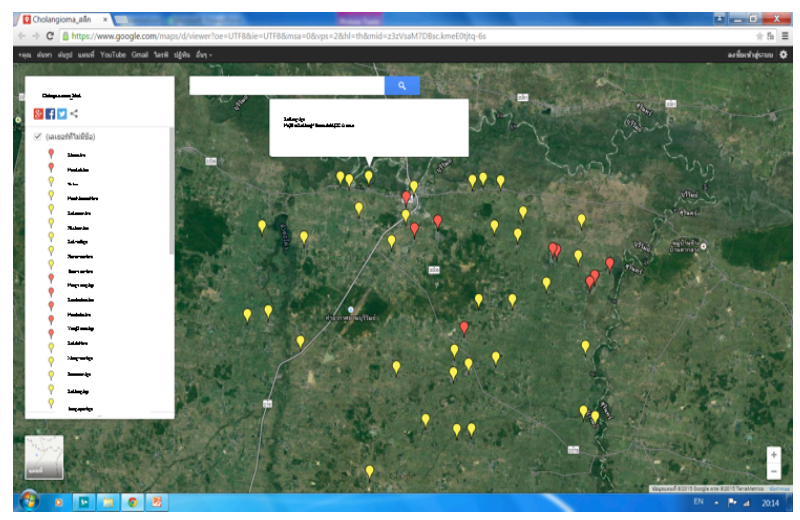

Figure 2. Distribution of CCA Cases in Sateuk district, Buriram Province, Thailand, During 2008-2012 Using Google EarthTM Software 


\section{Results}

Of 53 cases were diagnosed and indentified as a CCA paient in Stuek hospital of Buriram province, Thailand. Majority of CCA stages were IV and IIA (Table 1), with signed and symptoms presents of abdominal pain, vomited, jaundice, itching, and found the primary sclerosing cholangitis, cholethiasis. The incidence was 53.57 per 100,000 populations. CCA cases were reported yearly during 5 year (2008 and 2012). The attack rate was highest in 2011, the total number was 30 cases $(27.26$ per 100,000 populations). Gender specific attack rate was highest in male was 65.49 per 100,000 populations followed by female (30.8 per 100,000 populations), and male to female ratio was 2.12:1. Median age of cases was 67 years (IQR: 62-73 years). Majority of CCA cases were found in age group $>40$ year old (46.78 per 100,000 populations). The highest attack rate was observed in Thung Wang sub-district (161.36 per 100,000 populations) followed by Sakae sub-district (78.26 per 100,000 populations) and Mueang Kae sub-district (71.91 per 100,000 populations) (Table 2).

GE software is a usable tool for the geovisual analysis of the CCA distribution. Herein make various CCA epidemic maps based on GE, indicated that CCA epidemic maps are clear and visual. CCA cases were found in 43

Table 1. Stages of CCA Patients who were Treated in Satuek Hospital, Satuek District, Buriram Province, Thailand During 2008-2012

\begin{tabular}{lcc}
\hline CCA stage & No. Of cases & $\%$ \\
\hline IIA & 2 & 3.7 \\
IV & 51 & 96.3 \\
Total & 53 & 100 \\
\hline
\end{tabular}

Table 2. Reported Cases of CCA Patients who were Treated in Satuek Hospital, Satuek District, Buriram Province, Thailand During 2008-2012

\begin{tabular}{|c|c|c|c|}
\hline \multicolumn{2}{|l|}{ Categories } & \multirow{2}{*}{$\frac{\text { No. of cases }}{36}$} & \multirow{2}{*}{$\begin{array}{c}\text { Attack rate/ } \\
100,000 \text { pop. }\end{array}$} \\
\hline Sex & Male & & \\
\hline & Female & 17 & 30.8 \\
\hline \multirow[t]{2}{*}{ Age group } & $<40$ year & 1 & 0.9 \\
\hline & $>40$ year & 52 & 46.78 \\
\hline \multirow[t]{12}{*}{ Sub-district } & Thung Wang & 12 & 161.36 \\
\hline & Sakae & 6 & 78.26 \\
\hline & Mueang Kae & 6 & 71.91 \\
\hline & Sanam Chai & 3 & 54.18 \\
\hline & Satuek & 6 & 52.89 \\
\hline & Nikhom & 8 & 46.1 \\
\hline & Krasang & 2 & 32.75 \\
\hline & Don Mon & 2 & 31.86 \\
\hline & Nong Yai & 3 & 29.76 \\
\hline & Chum Saeng & 2 & 18.13 \\
\hline & Tha Muang & 1 & 17.08 \\
\hline & Ron Thong & 2 & 16.28 \\
\hline \multirow[t]{5}{*}{ Year } & 2008 & 2 & 1.81 \\
\hline & 2009 & 12 & 10.91 \\
\hline & 2010 & 1 & 0.91 \\
\hline & 2011 & 30 & 27.26 \\
\hline & 2012 & 8 & 7.27 \\
\hline Total & & 53 & 53.57 \\
\hline
\end{tabular}

villages of Satuek district as a GE map display; red color spot indicates the CCA 2 cases/village, and yellow color spot shows the CCA 1 cases/village. All spot described about the details of CCA case, consist of address number, village name, sub-district name, and number of CCA case (Figure 2).

GE map display vailable at https://www.google.com/ $\mathrm{maps} / \mathrm{d} / \mathrm{viewer}$ ?oe $=\mathrm{UTF} \& \& \mathrm{ie}=\mathrm{UTF} 8 \mathrm{msa}=0 \& \mathrm{vps}=2 \& \mathrm{~h}$ $\mathrm{l}=$ th\&mid=z3zVsaM7DBsc.kmeE0tjtq $-6 \mathrm{~s}$

\section{Discussion}

CCA is still a serious public health problem in the Northeast and North of Thailand. Worldwide incidence (cases/100,000) of CCA was reported, The data are relative to the period between 1977 to 2007, indicates that Thailand has a highest CCA especially in the Northeast (85.00 per $100,000)$, North $(14.6 .00$ per 100,000$)$, Central $(14.4$ per 100,000), and South (5.7 per 100,000$)$, respective; y. (Bragazzi et al., 2012). Recent study, of 53 cases were diagnosed and indentified as a CCA who were treated in Stuek hospital. The incidence was 53.57 per 100,000 populations, this figure indicates that Satuek district is a risk area of CCA, a severe health problems and economic on the population affected, similar to other known epidemic areas of Thailand (Sripa et al., 2011). Majority of CCA stages in Satuek district were IV and IIA, and they present the signed and symptoms with abdominal pain, vomited, jaundice, itching, and found the primary sclerosing cholangitis, cholethiasis. This figures are similar to Thunyaharn et al. (2013), most CCA patients see a physician at a late stage (III and IV) at Srinagarind Hospital, Khon Kaen University. Those in stage III and stage IV had a 6.78 fold higher mortality than the stage I and stage II cases. The incidence of CCA increases with age, and the disease is slightly more common in men than in women (Henson et al., 1992; Haswell-Elkins et al., 1994; Sripa et al., 2005; Kaewpitoon et al., 2008; Poomphakwaen, 2009). This article also found that the majority of CCA cases were age group $>40$ year old and gender specific attack rate was highest in male, and male to female ratio was 2.12:1.

Using geovisual analytics we were able to display and retrieve information from complex dataset efficiently. Instead of searching for patterns in a series of static maps or using numerical statistics, we created the set of interactive visualizations in order to explore and communicate results of analyses to the wider audience. The results of the geovisual analytics identified periodical patterns in the spread of the CCA cases. CCA cases were found in 43 villages of Satuek district as a GE map display. GE described about the details of CCA case, consists of address number, village name, sub-district name, and number of CCA cases, indicated that CCA epidemic maps are clear and visual. We prove that GE software is a usable tool for the geovisual analysis of the disease distribution. GE has many indisputable advantages mainly widespread, freely available, intuitive interface, space-time visualization capabilities and animations, communication of results, similar to previously publication were described (Wattanayingcharoenchai et al., 2011; Wang et al., 2014; 
Wannaporn Rattanasing et al

Kheifets et al., 2015; Marek et al., 2015).

CCA is still a serious health problem in Satuek district, Buriram province of Thailand. GE software is a usable tool for the geovisual analysis of the CCA distribution. The production process is very simple and easy to learn. It is suitable for the use in the home visit and further planning for CCA management strategy.

\section{Acknowledgements}

We would like to thank the National Research Council of Thailand for supported the grants Fiscal year 2010.

\section{References}

Bragazzi MC, Cardinale V, Carpino G, et al (2012). Cholangiocarcinoma: Epidemiology and risk factors. Transl Gastrointest Cancer, 1, 21-32.

Feldman M, Friedman LS, Brandt LJ (2006). Sleisenger and Fordtran's gastrointestinal and liver Disease $\left(8^{\text {th }}\right.$ ed.). saunders. pp. 1493-6.

Haswell-Elkins MR, Mairiang E, Mairiang P, et al (1994). Cross-sectional study of opisthorchis viverrini infection and cholangiocarcinoma in communities within a high-risk area in Northeast Thailand. Int J Cancer, 59, 505-9.

Henson D, Albores-Saavedra J, Corle D (1992). "Carcinoma of the extrahepatic bile ducts. Histologic types, stage of disease, grade, and survival rates". Cancer, 70, 1498-501.

Jongsuksuntigul P, Imsomboon T (2003). Opisthorchiasis control in Thailand. Acta Trop, 88, 229-32.

Kaewpitoon N, Kaewpitoon SJ, Pengsaa P, et al (2008). Opisthorchis viverrini: the carcinogenic human liver fluke. World J Gastroenterol, 14, 666-74.

Kheifets L, Crespi CM, Hooper C, et al (2015). Epidemiologic study of residential proximity to transmission lines and childhood cancer in California: description of design, epidemiologic methods and study population. J Expo Sci Environ Epidemiol, 25, 45-52.

Marek L, Tucek P, Paszto V (2015). Using geovisual analytics in Google Earth to understand disease distribution: a case study of campylobacteriosis in the czech republic (2008-2012). Int $J$ Health Geogr, 14, 7.

Parkin DM, Ohshima H, Srivatanakul P, Vatanasapt V (1993). Cholangiocarcinoma: epidemiology, mechanisms of carcinogenesis and prevention. Cancer Epidemiol Biomarkers Prev, 2, 537-44.

Parkin DM (2006). The global health burden of infectionassociated cancers in the year 2002. Int J Cancer, 118, 3030-44.

Poomphakwaen K, Promthet S, Kamsa-ard S, et al (2009). Risk factors for cholangiocarcinoma in KhonKaen, Thailand: A nested case-control study. Asian Pac J Cancer Prev, 10, 251-7.

Shin HR, Oh JK, Masuyer E, et al (2010). Epidemiology of cholangiocarcinoma: An update focusing on risk factors. Cancer Sci, 101, 579-85.

Sripa B, Yongvanit P, Pairojkul CH (2005). Etiology and pathogenesis cholangiocarcinoma: introduction to the association with liver fluke infection. Srinagarind Med J, 20, 122-34.

Sripa B, Pairojkul C (2008). Cholangiocarcinoma: lessons from Thailand. Curr Opin Gastroenterol, 24, 349-56.

Sripa B, Bethony JM, Sithithaworn P, et al (2011). Opisthorchiasis and Opisthorchis-associated cholangiocarcinoma in Thailand and Laos. Acta Trop, 120, 158-68.

Su C, Tsay S, Wu C, et al (1996). Factors influencing postoperative morbidity, mortality, and survival after resection for hilar cholangiocarcinoma. Ann Surg, 223, 384-94.

Thunyaharn N, Promthet S, Wiangnon S, et al (2013). Survival of cholangiocarcinoma patients in northeastern Thailand after supportive treatment. Asian Pac J Cancer Prev, 14, 7029-32.

Wang WC, Zhan T, Zhu YF (2014) A manufacture method of schistosomiasis epidemic maps based on Google Earth. Zhongguo Xue Xi Chong Bing Fang Zhi Za Zhi, 26, 96-8. 